\title{
Downregulation of SIRT6 by miR-34c-5p is associated with poor prognosis and promotes colon cancer proliferation through inhibiting apoptosis via the JAK2/STAT3 signaling pathway
}

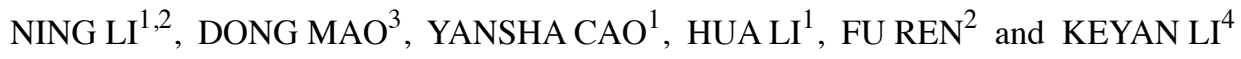 \\ Departments of ${ }^{1}$ Biochemistry and Molecular Biology and ${ }^{2}$ Biological Anthropology Institute, College of Basic Medicine, \\ Jinzhou Medical University, Jinzhou, Liaoning 121000; Departments of ${ }^{3}$ Large Intestine and ${ }^{4}$ Cardiology, \\ The First Affiliated Hospital of Jinzhou Medical University, Jinzhou Medical University, \\ Jinzhou, Liaoning 121000, P.R. China
}

Received October 20, 2017; Accepted February 22, 2018

DOI: $10.3892 /$ ijo.2018.4304

\begin{abstract}
Sirtuin 6 (SIRT6) is a member of the nicotinamide adenine dinucleotide positivity-dependent class III deacetylase sirtuin family. The present study aimed to explore the expression and function of SIRT6 in colon cancer. Furthermore, the partial mechanism underlying the dysregulation of SIRT6 was investigated. The results of immunohistochemistry demonstrated that SIRT6 was markedly downregulated in colon cancer tissues, and patients with high SIRT6 expression had a better prognosis than those who did not. The proliferation and apoptotic assays demonstrated that SIRT6 was able to suppress colon cancer cell proliferation and induce apoptosis via the Janus kinase 2 (JAK2)/signal transducer and activator of transcription 3 (STAT3) signaling pathway. MicroRNAs (miRNAs/miRs) are important non-coding RNAs, which have a critical role in the negative regulation of their target genes. Through bioinformatics analysis and further experiments, the results demonstrated that miR-34c-5p was not only dysregulated in colon cancer tissues but may also regulate SIRT6 expression via interaction with the 3'-untranslated region of SIRT6 mRNA. The proliferation and apoptotic assays indicated that miR-34c-5p could directly promote cell growth and inhibit apoptosis via activation of the JAK2/STAT3 signaling pathway, which was similar to silencing SIRT6. In conclusion, the results of the present study demonstrated that miR-34c-5p promoted colon cancer cell proliferation by targeting SIRT6 via activation of the JAK2/STAT3 signaling pathway. It may be hypothesized that SIRT6 is a potential biomarker for colon
\end{abstract}

Correspondence to: Mr. Keyan Li, Department of Cardiology, The First Affiliated Hospital of Jinzhou Medical University, Jinzhou Medical University, Section 5, 2 Renmin Road, Linghe, Jinzhou, Liaoning 121000, P.R. China

E-mail:157027083@qq.com

Key words: sirtuin 6, microRNA-34c-5p, colon cancer, prognosis, proliferation, apoptosis, Janus kinase 2/signal transducer and activator of transcription 3 cancer prognosis, and the miR-34c-5p/SIRT6/JAK2/STAT3 axis may provide novel insights into colon cancer treatment.

\section{Introduction}

Colon cancer is one of the top three most common types of cancer worldwide, and is associated with high levels of morbidity and mortality (1). Despite the development of colorectal endoscopy, the incidence of colon cancer has continued to rise. Numerous therapies are currently available for the treatment of colon cancer; however, the associated mortality rate remains largely unimproved. Therefore, the pathogenic mechanisms underlying the development and progression of colon cancer require further elucidation, in order to develop better therapeutic strategies.

Sirtuin 6 (SIRT6) is a member of the nicotinamide adenine dinucleotide positivity-dependent class III deacetylase sirtuin family, which is involved in various signaling pathways that regulate gene transcription and glucose homeostasis (2-4). In cancer research, SIRT6 is considered of great importance in the development and progression of numerous types of cancer $(5,6)$. SIRT6 has been reported to suppress liver cancer tumorigenesis in mice (7-9). Notably, SIRT6 has been revealed to act as an oncogene in skin and prostate cancer $(10,11)$. These previous findings suggest that its function may be tissuedependent; however, the expression of SIRT6 in patients with colon cancer and its association with clinical features remain to be fully elucidated. Furthermore, the mechanisms underlying the function of SIRT6 in colon cancer and its dysregulation remain to be elucidated.

MicroRNAs (miRNAs/miRNAs) are a large family of short single-stranded endogenous and non-coding RNAs, which contain 19-22 nucleotides. miRNAs can affect gene expression at the transcriptional or post-transcriptional level by interacting with the 3'-untranslated region (UTR) of target gene mRNAs $(12,13)$. Increasing bioinformatics evidence and subsequent functional assays have revealed that miRNAs serve key roles in numerous biological processes in several types of cancer, including apoptosis and proliferation (14). With the development of bioinformatics, differentially expressed 
miRNAs in colon cancer tissues compared with in adjacent tissues have been detected (15); however, with the exception of miR-34a, miRNAs that regulate SIRT6 expression remain unknown (16).

In the present study, the expression levels of SIRT6 were detected in colon cancer tissues and adjacent tissues by immunohistochemistry (IHC), and the correlation between SIRT6 and clinical features was investigated. Cell counting kit-8 (CCK-8) and apoptotic assays were used to explore the effects of SIRT6 on proliferation and apoptosis. Using bioinformatics analysis, the present study identified miR-34c-5p as the most likely miRNA to interact with SIRT6 mRNA. Subsequently, it was confirmed that miR-34c-5p could bind to the 3'-UTR of SIRT6 mRNA, using human colon cancer cell lines RKO and HCT116. Furthermore, the ectopic expression of miR-34c-5p promoted tumor cell proliferation and inhibited apoptosis of colon cancer cells via activation of the Janus kinase 2 (JAK2)/signal transducer and activator of transcription 3 (STAT3) signaling pathway, which was consistent with the effects of SIRT6 downregulation.

\section{Materials and methods}

Tissue chip and IHC. The tissue chip (HColA180Su09) used in the present study comprised 100 colon cancer tissues and 80 corresponding adjacent colon tissues $(1.5 \mathrm{~cm}$ away from the resection edge of the tumor; no residual tumor confirmed), and was purchased from Shanghai Outdo Biotech Co., Ltd. (Shanghai, China). The patients were operated on between May 2006 and May 2007, and the last follow-up was July 2015. All patients were pathologically diagnosed with colon cancer and did not receive treatment prior to surgery. The details of tissue chip production, including information regarding informed consent and ethics committee approval, and the IHC protocol were previously elaborated by Ding et al (17). The antibody used for IHC was as follows: Anti-SIRT6 (dilution 1:100; cat. no. 13572-1-AP; Proteintech, Rosemont, IL, USA). The solvent [antibody diluent (Dako, Glostrup, Denmark)] of the primary antibody as a negative control. In the present study, three tissue points, which failed to be stained, and their matched tissues were excluded.

Immunostaining was evaluated by two pathologists who were blinded to the clinical information. The proportion of positive cells was categorized as follows: $<25 \%$, score $1 ; 26-50 \%$, score $2 ; 51-75 \%$, score $3 ; 76-100 \%$, score 4 . In addition, the extent of staining was scored as follows: No staining, 1; light yellow staining, 2; light brown staining, 3; brown staining, 4 . The average of the two scores was used to define low expression (average $<6$ ) or high expression (average $\geq 6$ ).

Bioinformatics analysis. The miRNA microarray dataset GSE35982, using the GPL14767 microarray platform, was downloaded from the National Center for Biotechnology Information Gene Expression Omnibus (GEO; http://www. ncbi.nlm.nih.gov/geo/). The experimental design was described by $\mathrm{Fu}$ et al (15). The known human miRNAs registered in miRBase (Release 21; http://www.mirbase.org/) were used to analyze the differential expression of miRNAs with limma package (18); if numerous probes corresponded to one gene, their expression values were treated as averages. llog fold changel $>1.5$ and $\mathrm{P}<0.05$ were used to determine significant differentially expressed miRNAs between cancer and matched adjacent tissues. The miRNAs possibly targeting SIRT6 were predicted using miRanda (http://www.microrna. org/microrna/home.do) and MicroCosm Targets (http://www. ebi.ac.uk/enright-srv/microcosm/htdocs/targets/v5/).

Cell culture. The human colon cancer cell lines RKO, HT-29, SW620, COLO 205 and HCT116 were purchased from the Cell Bank of the Chinese Academy of Sciences (Shanghai, China). All cells were grown in Roswell Park Memorial Institute-1640 medium supplemented with $10 \%$ fetal bovine serum (both from Gibco; Thermo Fisher Scientific, Inc., Waltham, MA, USA) and $100 \mathrm{U} / \mathrm{ml}$ penicillin $+100 \mu \mathrm{g} / \mathrm{ml}$ streptomycin. Cells were cultured at $37^{\circ} \mathrm{C}$ in an incubator containing $5 \% \mathrm{CO}_{2}$. To suppress the JAK2/STAT3 signaling pathway, cells were treated with $50 \mu \mathrm{M}$ AG490 (a JAK2 protein tyrosine kinase inhibitor, dissolved in dimethyl sulfoxide) (Selleck Chemicals, Houston, TX, USA) 1 day post-transfection for at least $24 \mathrm{~h}$ at $37^{\circ} \mathrm{C}$. The solvent of AG490 $(1 \mu \mathrm{l})$, dimethyl sulfoxide, was used to treat the negative control group.

Synthetic RNA oligonucleotides and transient transfection. miRNA inhibitors, miRNA mimics, negative control (NC), SIRT6 small interfering (si)RNA (si-SIRT6), NC-siRNA, SIRT6 overexpression plasmid vector with pcDNA 3.1 and its control plasmid vector were all obtained from Shanghai GenePharma Co., Ltd. (Shanghai, China). The sequences of oligonucleotides were follow: miRNA mimics, 5'-AGGCAGUGUAGUUAGCU GAUUGC-3' and 5'-AAUCACUAACCACACGGCCAGG-3'; miRNA inhibitors, 5'-GCAAUCAGCUAACUACACUG CCU-3'; miRNA NC, 5'-CAGUACUUUUGUGUAGUACAA-3'; si-SIRT6, 5'-TCATGACCCGGCTCATGAA-3'; NC-siRNA, 5'-TCACCCATCGGTACGTGAA-3'. Briefly, RKO and HCT116 cells $\left(200 \times 10^{3}\right.$ cells/well) in 6-well plates were transfected using Lipofectamine ${ }^{\circledR} 2000$ (Invitrogen; Thermo Fisher Scientific, Inc.) according to the manufacturer's protocol. The oligonucleotide doses used were the largest doses suggested by the manufacturer's protocols. All transfections were transient; the cells were not harvested for subsequent assays until $48 \mathrm{~h}$ post-transfection.

RNA extraction and reverse transcription-quantitative polymerase chain reaction ( $R T-q P C R)$. Total RNA was extracted from the cells using TRIzol ${ }^{\circledR}$ reagent 2000 (Invitrogen; Thermo Fisher Scientific, Inc.) according to the manufacturer's protocol. miRNA RT-qPCR was performed using Hairpin-it miRNAs qPCR Quantitation kit (Shanghai GenePharma Co., Ltd.) according to the manufacturer's protocol. For mRNA RT-qPCR, RT was performed using the PrimeScript RT Reagent kit and RT-qPCR was conducted using the QuantiTect SYBR-Green PCR kit (both from Takara Biotechnology Co., Ltd., Dalian, China) on an ABI 7500 Fast System Thermocycler (Thermo Fisher Scientific, Inc.), according to the manufacturers' protocols. qPCR for mRNA expression was conducted as follows: Initial denaturation at $95^{\circ} \mathrm{C}$ for $30 \mathrm{sec}$, followed by 40 cycles of annealing at $95^{\circ} \mathrm{C}$ for $5 \mathrm{sec}$ and extension at $60^{\circ} \mathrm{C}$ for $30 \mathrm{sec}$. qPCR for miRNA expression was conducted as follows: Initial denaturation at $95^{\circ} \mathrm{C}$ for $3 \mathrm{~min}$, followed by 40 cycles of annealing at $95^{\circ} \mathrm{C}$ for $12 \mathrm{sec}$ and extension at $62^{\circ} \mathrm{C}$ for $60 \mathrm{sec}$. 
The relative miRNA expression of each gene was normalized to U6 RNA levels, and the relative mRNA expression levels were normalized to GAPDH mRNA expression. Triplicate reactions were performed, and the data were analyzed using the $2^{-\Delta \Delta \mathrm{Cq}}$ method (19). The primers were synthesized by Shanghai GenePharma Co., Ltd. The primer sequences were as follows: miR-34c-5p, forward, 5'-tgccagttagtagcccagaagcaa-3' and reverse, 5'-tgatgtgccagggaagaaagccta-3'; SIRT6, forward, 5'-gcg tgtggagtatttggatgac-3' and reverse, 5'-agtgtgatgatggtgagga tgg-3'; and GAPDH, forward, 5'-ttctacaatgagctgcgtgtggct-3' and reverse, 5'-tagcacagcetggatagcaacgta-3'. The U6 primers were purchased from Sangon Biotech Co., Ltd. (Shanghai, China) and the primers were: Forward, 5'-ATTGGAACGATACAG AGAAGATT-3' and reverse, 5'-GGAACGCTTCACGAAT TTG-3'. For comparison, the relative expression levels of the blank group were set to 1 .

Protein extraction and western blot analysis. Colon cancer cells were washed twice with PBS and lysed with radioimmunoprecipitation assay buffer (Beyotime Institute of Biotechnology, Beijing, China). Protein concentrations were determined using a bicinchoninic acid protein kit (Thermo Fisher Scientific, Inc.). Total protein $(40 \mu \mathrm{g})$ was separated by $10 \%$ SDS-PAGE and proteins were transferred to polyvinylidene difluoride membranes. The membranes were blocked with $5 \%$ defatted milk in Tris-buffered saline containing $0.5 \%$ Tween-20 at room temperature for $2 \mathrm{~h}$. The membranes were then incubated with primary antibodies, including anti-SIRT6 (ab191385; dilution 1:2,000), anti-phosphorylated-JAK2 (ab32101; dilution 1:2,000), anti-JAK2 (ab108596; dilution 1:5,000), anti-phosphorylated-STAT3 (ab76315; dilution 1:3,000), anti-STAT3 (ab68153; dilution 1:1,000), anti-tubulin (ab6046; dilution 1:500) and anti-GAPDH (ab9485; dilution 1:1,000) (all from Abcam, Cambridge, MA, USA), at $4^{\circ} \mathrm{C}$ overnight. Finally, the membranes were washed and incubated with the horseradish peroxidase-conjugated secondary antibody (ab6721; dilution 1:5,000; Abcam) for $2 \mathrm{~h}$ at room temperature. The protein bands were detected using an electrochemiluminescence substrate (Thermo Fisher Scientific, Inc.) via a chemiluminescence method (LAS-3000; Fujifilm Corporation, Tokyo, Japan). The details of western blot analysis of the JAK2/STAT3 signal pathway are clearly described by Feng et al (20).

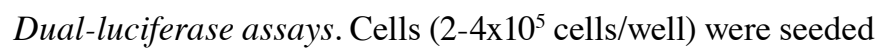
into 6-well plates and cultured overnight. The cells were then transfected with the control vector, wild-type or mutant SIRT6 luciferase plasmids ( $1 \mu \mathrm{g}$ wild-type or mutant plasmids per well; Shanghai GeneChem Co., Ltd., Shanghai, China) using Lipofectamine ${ }^{\circledR} 2000$ (Invitrogen; Thermo Fisher Scientific, Inc.). The wild-type plasmid contained the predicted binding site of miR-34c-5p, whereas the mutant plasmid contained a mutated sequence of the predicted binding site of miR-34c-5p (5'-CATCAGATCACCGATCCACGCC-3'). In addition, cells were cotransfected with miR-34c-5p mimics, inhibitors or NC. Relative luciferase activities were standardized to the activity of the Renilla luciferase reporter gene and were assessed $24 \mathrm{~h}$ following cotransfection. Firefly and Renilla luciferase activities were quantified using a dual-luciferase assay system (Promega Corporation, Madison, WI, USA) according to the manufacturer's protocol. For the ease of comparison, the luciferase values of cells transfected with $\mathrm{NC}+$ control vector were set to 1 .

Cell proliferation assays. Cell proliferation was measured using CCK-8 (Beyotime Institute of Biotechnology). Post-transfection, cells were seeded in 96-well plates at a density of $3-5 \times 10^{3}$ cells/well. CCK-8 (10 $\mu \mathrm{l} /$ well $)$ was added at various time points $\left(0,1,2\right.$ and 3 days) and incubated at $37^{\circ} \mathrm{C}$ for $2 \mathrm{~h}$. To estimate the number of viable cells, the absorbance of each well was detected at $450 \mathrm{~nm}$ using a microplate reader (Bio-Rad Laboratories, Inc., Hercules, CA, USA). The assays were performed in triplicate to reduce random errors.

Colony formation assays. The colony formation assays were used to estimate in vitro tumorigenicity. A total of 200 cells were seeded into 6-well plates post-transfection. The cells were cultured for 7 days at $37^{\circ} \mathrm{C}$ until most of the single colonies contained $>50$ cells. Subsequently, the cells were washed with PBS, fixed with $5 \mathrm{ml} 100 \%$ paraformaldehyde for $15 \mathrm{~min}$ and stained with $0.1 \%$ crystal violet for $30 \mathrm{~min}$ at room temperature. The number of colonies was counted under a light microscope.

Cell apoptosis analysis. Flow cytometric analysis of apoptosis was performed using an Annexin V/fluorescein isothiocyanate (FITC) and propidium iodide (PI) apoptosis detection kit (BD Biosciences, San Jose, CA, USA) following transfection for $48 \mathrm{~h}$. The cells were harvested using trypsin, washed twice with cold PBS and suspended in binding buffer. The cell suspension $(300 \mu \mathrm{l})$ was incubated with Annexin V/FITC $(5 \mathrm{ml})$ in a light-resistant container at room temperature for $15 \mathrm{~min}$. Finally, PI $(2 \mathrm{ml})$ was added $5 \mathrm{~min}$ prior to detection using a flow cytometer (Bio-Rad Laboratories, Inc.). Each experiment was performed at least three times.

Statistical analysis. The difference in SIRT6 expression between cancerous and adjacent tissues was analyzed by $\chi^{2}$ test. Overall survival was analyzed by Kaplan-Meier analysis and log-rank test. Univariate analysis and multivariate survival analysis were performed using a Cox regression model. The association between SIRT6 and clinical characteristics was explored using Spearman rank correlation. Other data are presented as the means \pm standard deviation, and were analyzed by Student's t-test when comparing two groups or two-way analysis of variance followed by Student-Newman-Keuls-q test. Statistical analyses were processed using SPSS 23.0 software (IBM Corporation, Armonk, NY, USA) and GraphPad Prism 5.0 (GraphPad Software, La Jolla, CA, USA). P<0.05 was considered to indicate a statistically significant difference. Bioinformatics analysis was processed using $\mathrm{R}$ program version 3.2.2 (R Foundation for Statistical Computing, Vienna, Austria; http://www.r-project.org/).

\section{Results}

SIRT6 is downregulated in colon cancer tissues. SIRT6 expression was assessed in cancerous and adjacent tissues by IHC, as shown in Fig. 1 and Table I. SIRT6 was revealed to be predominantly expressed in the nucleus and was significantly overexpressed in adjacent tissues compared with in cancerous 

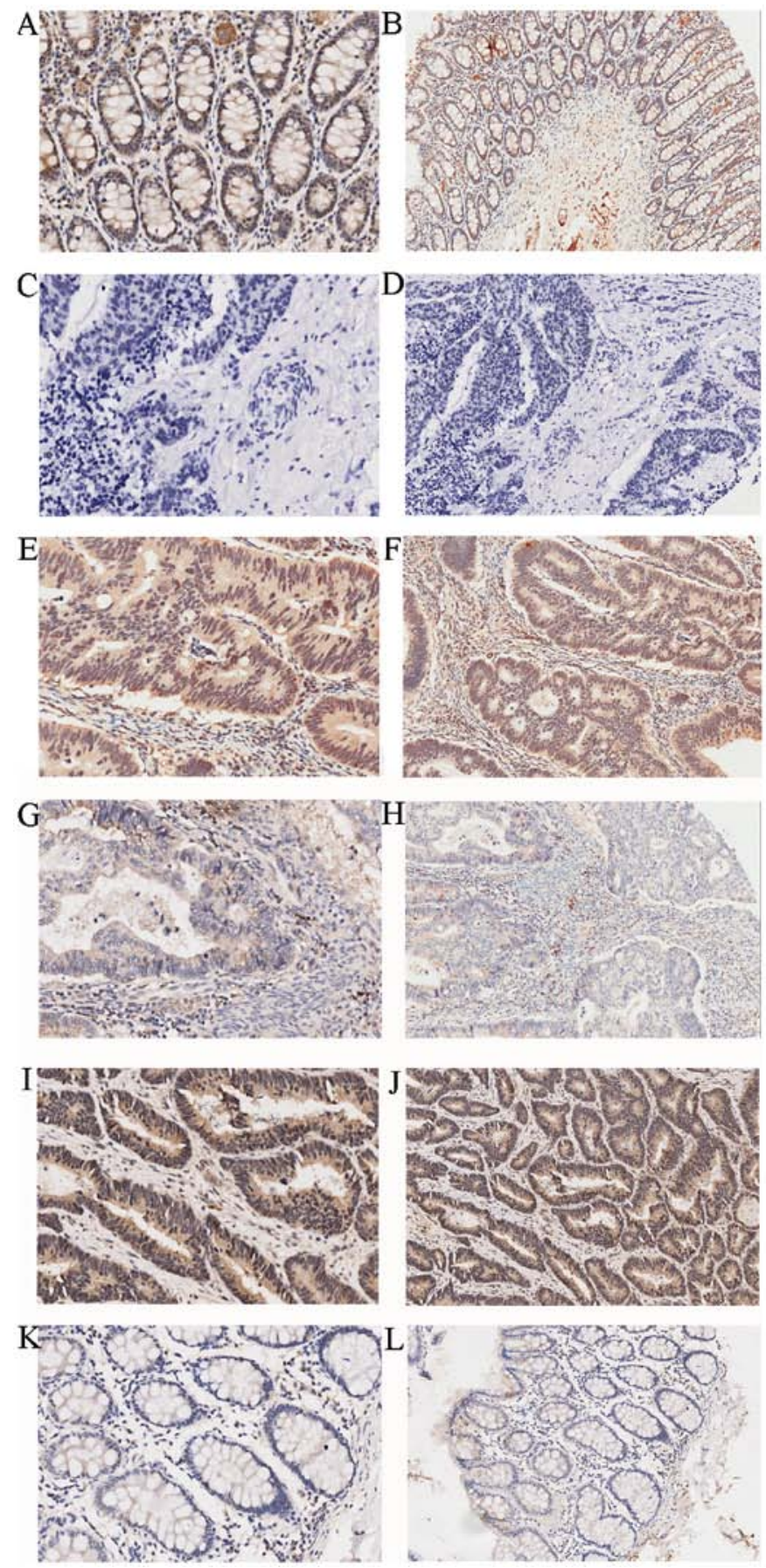

Figure 1. Immunohistochemical staining of SIRT6. High expression of SIRT6 in adjacent colon tissues: (A) Magnification, x200; (B) magnification, x100. Negative control: (C) Magnification, x200; (D) magnification, x100. High expression of SIRT6 in colon cancer tissues: (E) Magnification, x200 (F) magnification, $x 100$. Low expression of SIRT6 in colon cancer tissues: (G) Magnification, x200; (H) magnification, x100. High expression of SIRT6 in adjacent tissues: (I) Magnification, x200; (J) magnification, x100. Low expression of SIRT6 in adjacent tissues: (K) Magnification, x200; (L) magnification, x100. SIRT6, sirtuin 6.

tissues $(\mathrm{P}<0.05)$. The association between SIRT6 and clinical features, such as TNM stage and pathological grade, are shown in Table II; the tissue points that failed to be stained were excluded. The results indicated that the expression of SIRT6 was negatively associated with T stage, which is mainly affected by proliferation and apoptosis $(\mathrm{P}<0.05)$. Furthermore, univariate survival analysis was conducted and the results
Table I. Differential expression of SIRT6 in paired cancerous and adjacent tissues.

\begin{tabular}{lccccc}
\hline \multicolumn{5}{c}{ SIRT6 expression } & \\
\cline { 3 - 4 } Tissue & $\mathrm{n}$ & High & Low & $\chi^{2}$ value & P-value \\
\hline Cancerous & 77 & 37 & 40 & 5.1970 & $0.02^{\mathrm{a}}$ \\
Adjacent & 77 & 51 & 26 & & \\
\hline
\end{tabular}

${ }^{a} \mathrm{P}<0.05$. SIRT6, sirtuin 6.

Table II. Correlation between SIRT6 expression and clinical features.

\begin{tabular}{|c|c|c|c|c|c|}
\hline \multirow[b]{2}{*}{ Characteristic } & \multicolumn{2}{|c|}{ SIRT6 expression } & \multirow[b]{2}{*}{ Total } & \multirow[b]{2}{*}{$\mathrm{r}_{\mathrm{s}}$} & \multirow[b]{2}{*}{ P-value } \\
\hline & High & Low & & & \\
\hline Sex & & & & -0.141 & 0.168 \\
\hline Female & 26 & 17 & 43 & & \\
\hline Male & 25 & 29 & 54 & & \\
\hline Age (years) & & & & -0.024 & 0.822 \\
\hline$\leq 70$ & 25 & 17 & 42 & & \\
\hline$>70$ & 22 & 28 & 50 & & \\
\hline Null & & & 5 & & \\
\hline Grade & & & & -0.113 & 0.272 \\
\hline I & 3 & 4 & 7 & & \\
\hline II & 32 & 21 & 53 & & \\
\hline III & 16 & 21 & 37 & & \\
\hline T stage & & & & -0.241 & $0.02^{\mathrm{a}}$ \\
\hline $\mathrm{T} 1$ & 1 & 0 & 1 & & \\
\hline $\mathrm{T} 2$ & 5 & 0 & 5 & & \\
\hline $\mathrm{T} 3$ & 38 & 35 & 73 & & \\
\hline $\mathrm{T} 4$ & 5 & 9 & 14 & & \\
\hline Null & & & 4 & & \\
\hline N stage & & & & -0.164 & 0.113 \\
\hline No & 34 & 24 & 58 & & \\
\hline N1 & 15 & 12 & 27 & & \\
\hline N2 & 2 & 8 & 10 & & \\
\hline Null & & & 2 & & \\
\hline M stage & & & & -0.188 & 0.065 \\
\hline M0 & 51 & 43 & 94 & & \\
\hline M1 & 0 & 3 & 3 & & \\
\hline TNM stage & & & & -0.168 & 0.104 \\
\hline I & 4 & 1 & 5 & & \\
\hline II & 30 & 23 & 53 & & \\
\hline III & 17 & 17 & 34 & & \\
\hline IV & 0 & 3 & 3 & & \\
\hline Null & & & 2 & & \\
\hline
\end{tabular}

a $\mathrm{P}<0.05$. SIRT6, sirtuin 6 .

demonstrated that the patients with high SIRT6 expression had a better prognosis relative to those with a lower expression of 
Table III. Univariate and multivariate survival analyses.

\begin{tabular}{|c|c|c|c|c|c|c|}
\hline \multirow[b]{2}{*}{ Variable } & \multicolumn{3}{|c|}{ Univariate analysis } & \multicolumn{3}{|c|}{ Multivariate analysis } \\
\hline & HR & $95 \% \mathrm{CI}$ & P-value & HR & $95 \% \mathrm{CI}$ & P-value \\
\hline Sirtuin 6 expression & 0.475 & $0.282-0.799$ & $0.005^{\mathrm{a}}$ & 0.531 & $0.301-0.936$ & $0.029^{\mathrm{a}}$ \\
\hline Sex & 1.052 & $0.627-1.763$ & 0.849 & & & \\
\hline Age (years) & 1.955 & $1.132-3.373$ & $0.016^{\mathrm{a}}$ & 2.399 & $1.297-4.437$ & $0.005^{\mathrm{a}}$ \\
\hline T stage & 1.540 & $0.861-2.754$ & 0.146 & & & \\
\hline $\mathrm{N}$ stage & 2.233 & $1.553-3.213$ & $<0.001^{\mathrm{a}}$ & 1.808 & $0.823-3.971$ & 0.140 \\
\hline M stage & 13.908 & $3.680-46.626$ & $<0.001^{\mathrm{a}}$ & 1.972 & $0.424-9.173$ & 0.387 \\
\hline TNM stage & 2.790 & $1.756-4.431$ & $<0.001^{\mathrm{a}}$ & 1.136 & $0.441-2.926$ & 0.791 \\
\hline Grade & 2.664 & $1.653-4.296$ & $<0.001^{\mathrm{a}}$ & 2.033 & $1.221-3.386$ & $0.006^{\mathrm{a}}$ \\
\hline
\end{tabular}

${ }^{\mathrm{a}} \mathrm{P}<0.05$. CI, confidence interval; HR, hazard ratio.

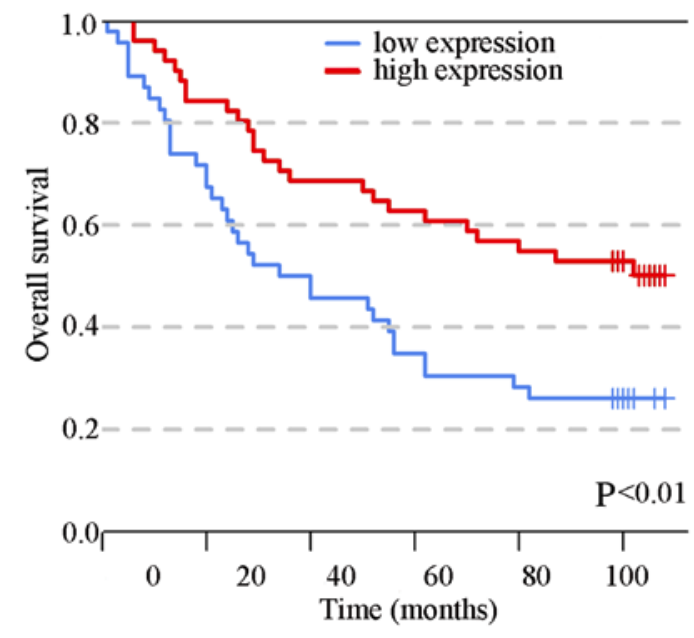

Figure 2. Kaplan-Meier analysis of overall survival (months) in 97 patients with colon cancer with high and low sirtuin 6 expression. Patients with high SIRT6 expression had a better prognosis than those with low expression (log-rank test; $\mathrm{P}<0.01)$.

SIRT6 (Fig. 2; 26.1 vs. 50.2\%, $\mathrm{P}<0.01$ ). In addition, $\mathrm{N}$ stage, $\mathrm{M}$ stage, TNM stage, age and grade were associated with the prognosis of colon cancer. To determine whether SIRT6 is an independent prognostic factor, these variables, which were associated with prognosis, were included in a multivariate Cox regression analysis; the results demonstrated that SIRT6 expression was a protective independent prognostic factor. In addition, age and grade were isolated factors harmful to the prognosis of patients with colon cancer (Table III).

SIRT6 inhibits colon cancer cell proliferation and promotes apoptosis. Thorough western blot analysis, it was demonstrated that SIRT6 was highly expressed in RKO cells and lowly expressed in HCT116 cells (Fig. 3A). To explore the role of SIRT6 in colon cancer, HCT116 and RKO cells were transfected with si-SIRT6, NC-siRNA, SIRT6 overexpression plasmid vector or control plasmid vector. SIRT6 was overexpressed in the HCT116 cell line and was knocked down in the RKO cell line. Transfection efficiency was confirmed, as shown in Fig. 3B and C. The results of CCK-8 assays demonstrated that overexpression of SIRT6 significantly inhibited cell viability, whereas SIRT6 knockdown had the opposite effect (Fig. 3D; P<0.05). Furthermore, through apoptotic analysis, upregulation of SIRT6 was revealed to markedly increase cell apoptosis, whereas SIRT6 knockdown suppressed it (Fig. 3E and F). On the basis of colony formation, enhancing the expression of SIRT6 significantly reduced the colony-forming ability of cells, whereas SIRT6 knockdown exhibited the opposite effects (Fig. 3G and H).

JAK2/STAT3 signaling is suppressed in colon cancer cells in response to SIRT6 overexpression. Previous study has revealed that the JAK2/STAT3 signaling pathway is highly activated in colon cancer, and contributes to proliferation, migration, invasion, cell cycle progression and angiogenesis (21-24). The association between SIRT6 and JAK2/STAT3 has been confirmed in other cancers; however, to the best of our knowledge, it has not been reported in colon cancer $(20,25)$. Therefore, the present study aimed to determine the effects of SIRT6 overexpression on the JAK2/STAT3 signaling pathway. The results indicated that SIRT6 overexpression markedly reduced the phosphorylation of JAK2 and STAT3 compared with in the control cells, whereas silencing SIRT6 increased the phosphorylation of JAK2 and STAT3 (Fig. 4A). These results indicated that SIRT6 may suppress proliferation and induce apoptosis via inactivation of the JAK2/STAT3 signaling pathway in colon cancer cells.

The JAK2 inhibitor AG490 was used to further confirm whether SIRT6 may serve a role in the JAK2/STAT3 signaling pathway. RKO cells transfected with si-SIRT6 were treated with AG490. As shown in Fig. 4B, AG490 markedly decreased the expression levels of phosphorylated (p)-JAK2 and p-STAT3, whereas the inhibitory effects were abolished by si-SIRT6. Furthermore, SIRT6 downregulation promoted the proliferation of cells and inhibited apoptosis, whereas the JAK2 inhibitor exhibited the opposite effects. Furthermore, the effects of AG490 on cell proliferation and apoptosis were counteracted by SIRT6 knockdown (Fig. 4C-E).

Bioinformatics analysis. miRNAs are major regulators of gene expression. To explore why SIRT6 is downregulated in colon 
A

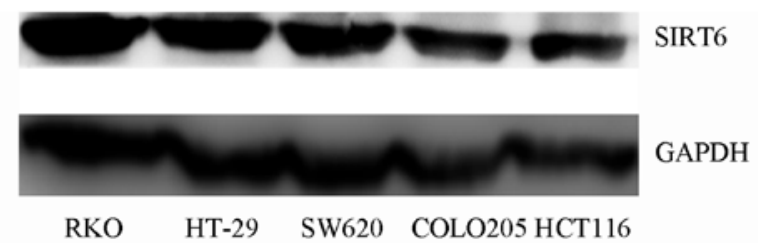

B

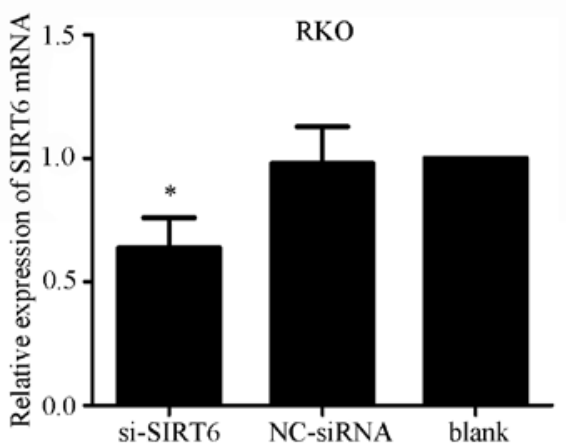

$\mathrm{C}$

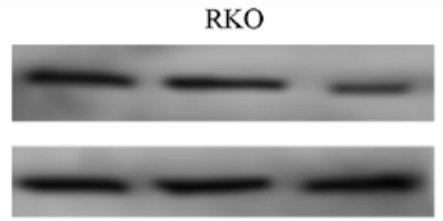

blank NC-siRNA si-SIRT6

SIRT6

GAPDH

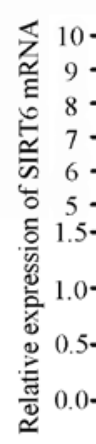

HCT116

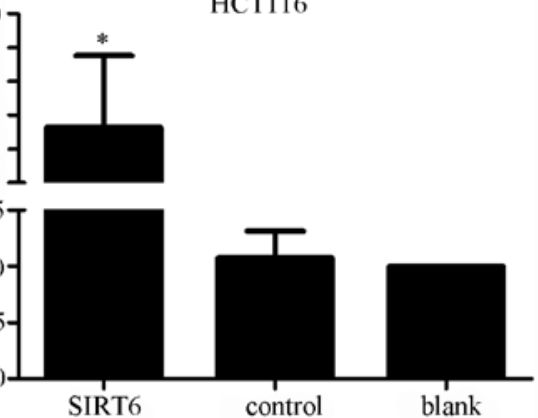

HCT116

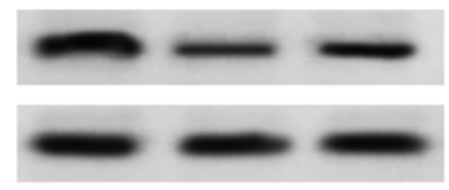

SIRT6

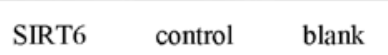

GAPDH
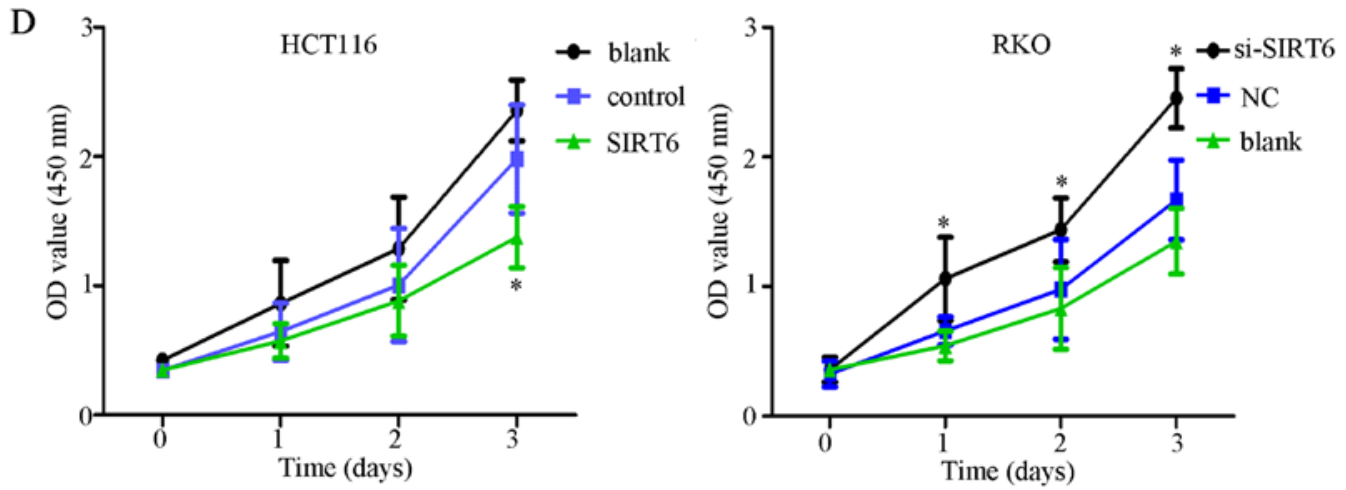

Figure 3. Effects of SIRT6 on colon cancer cell lines. (A) Expression of SIRT6 in different colon cancer cell lines. The RKO cell line had the highest expression and the HCT116 cell line had the lowest expression. (B) mRNA expression levels of SIRT6 after silencing or overexpression were evaluated by quantitative polymerase chain reaction to confirm the efficiency of transfection. si-SIRT6 markedly downregulated the expression of SIRT6 mRNA in RKO cells, and the SIRT6 overexpression plasmid vector increased the expression of SIRT6 in HCT116 cells. (C) Expression of SIRT6 after silencing or overexpression was assessed by western blot analysis, to confirm the efficiency of transfection. si-SIRT6 markedly downregulated the expression of SIRT6 in RKO cells, and the SIRT6 overexpression plasmid vector increased the expression of SIRT6 in HCT116 cells. (D) SIRT6 overexpression inhibited cell growth compared with in the control groups, whereas silencing SIRT6 promoted cell proliferation compared with in the control groups; "P<0.05 vs. the NC, or control or blank groups.

cancer, the present study determined whether miRNAs may account for it. The results from a miRNA microarray analysis suggested that 10 miRNAs were significantly differentially expressed in colon cancer (Fig. 5A). Subsequently, miRNAs that possibly targeted SIRT6 were predicted by miRanda and MicroCosm. Notably, miR-34a and miR-34c-5p were not only dysregulated in colon cancer but were also predicted to potentially target the 3'-UTR of SIRT6 (Fig. 5B). Furthermore, the interaction between miR-34a and SIRT6 mRNA has been reported by previous studies $(10,16)$. The possible binding sites between SIRT6 mRNA and miR-34c-5p are shown in Fig. 5C.

SIRT6 is a direct target of miR-34c-5p. A previous study reported that the expression levels of miR-34c-5p were increased in colorectal cancer tissues (26). To determine whether miR-34c-5p could interact with the 3'-UTR of SIRT6, miR-34c-5p and NC mimics and inhibitors were transfected into RKO and HCT116 cell lines. The transfection efficiency was measured by qPCR (Fig. 6A) and western blot analysis. The results demonstrated that miR-34c-5p overexpression inhibited the expression of SIRT6, whereas miR-34c-5p knockdown exhibited the opposite effect, thus indicating that miR-34c-5p may be a specific miRNA that targets SIRT6 in colon cancer cells (Fig. 6B). Subsequently, luciferase reporter assays were performed to determine whether miR-34c-5p acts on the 3'-UTR of SIRT6 mRNA. Control, wild-type and mutant vectors, alongside Renilla luciferase reporter genes, were transfected into colon cancer cells together with miR-34c-5p mimics, inhibitors or NC. The results demonstrated that relative luciferase activity was significantly 

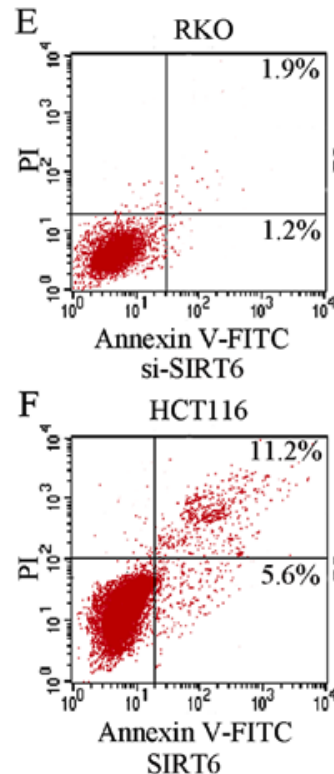

G

RKO

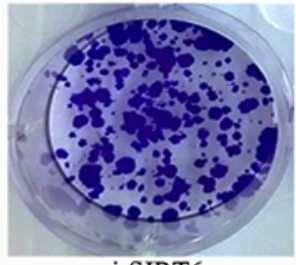

si-SIRT6

$\mathrm{H}$

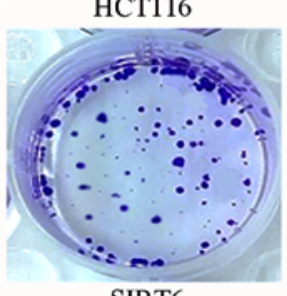

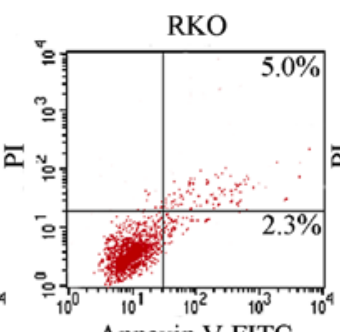

Annexin V-FITC

C-SiRN

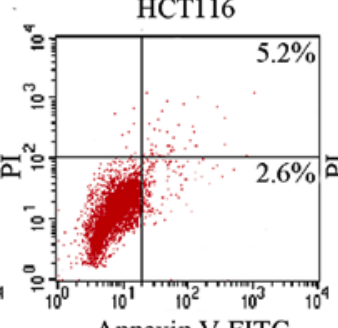

Annexin V-FITC control

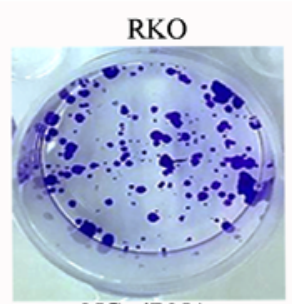

NC-siRNA

HCT116

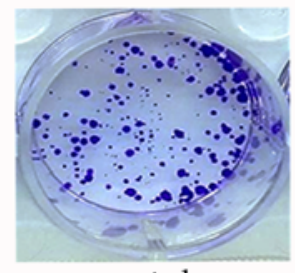

control

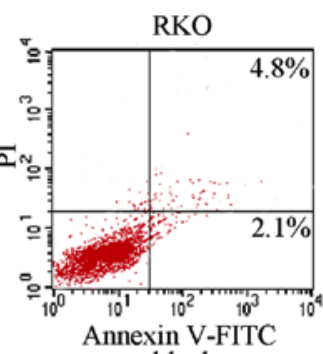

blank

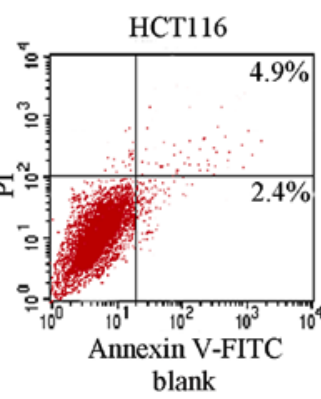

RKO

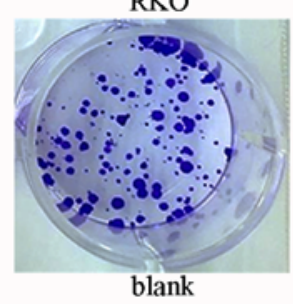

HCT116

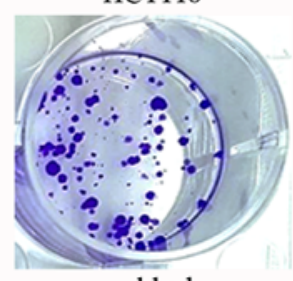

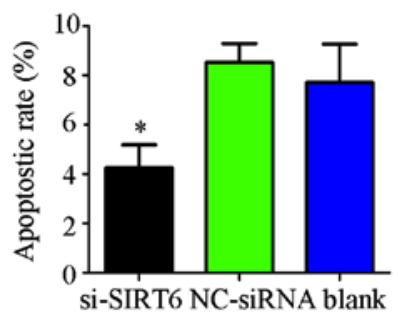
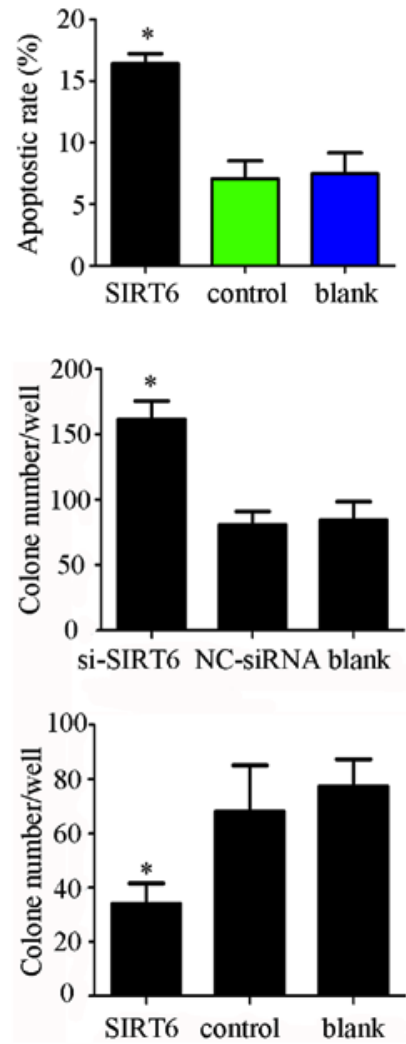

Figure 3. Continued. (E and F) Annexin V-FITC/PI was used to detect apoptosis after silencing SIRT6 in RKO cells or overexpressing SIRT6 in HCT116 cells Cell apoptosis was elevated in the SIRT6 group and decreased in the si-SIRT6 group compared with in the control groups; ${ }^{2} \mathrm{P}<0.05$ vs. the NC-siRNA, control or blank groups. ( $\mathrm{G}$ and $\mathrm{H}$ ) Colony formation assays indicated that silencing SIRT6 enhanced the colony-forming ability of cells, whereas overexpression of SIRT6 exhibited the opposite effect; " $\mathrm{P}<0.05$ vs. the NC-siRNA, control or blank groups. FITC, fluorescein isothiocyanate; NC, negative control; OD, optical density; PI, propidium iodide; si/siRNA, small interfering RNA; SIRT6, sirtuin 6.

decreased in the mimics + wild-type group and increased in the inhibitors + wild-type group. However, no significant alteration in relative luminescence intensities was detected in the other groups (Fig. 6C and D). These findings suggested that miR-34c-5p may bind directly to the 3'-UTR of SIRT6 mRNA and suppress SIRT6 expression in colon cancer cells.

Elevated expression of miR-34c-5p facilitates proliferation and inhibits apoptosis of colon cancer cells. To further confirm whether the functions of miR-34c-5p are contrary to SIRT6, miR-34c-5p mimics, inhibitors and NC were transfected into cells, and CCK- 8 assays were performed. The results indicated that transfection with miR-34c-5p mimics significantly facilitated cell growth, whereas transfection with miR-34c-5p inhibitors had the opposite effect, compared with in the control groups (Fig. 7A; $\mathrm{P}<0.05$ ). To explore the mechanism underlying the effects of miR-34c-5p on promoting cell proliferation, apoptosis and colony formation assays were performed on cells transfected with miR-34c-5p mimics, inhibitors or NC. Flow cytometry suggested that the percentage of apoptotic cells was significantly lower in the mimic group compared with in the control groups, whereas the levels of cell apoptosis were elevated in cells exposed to inhibitors (Fig. 7B and $\mathrm{C} ; \mathrm{P}<0.05$ ). The results of colony formation assays indicated that miR-34c-5p inhibitors weakened colony-forming ability (Fig. 7D and E). These findings suggested that increased miR-34c-5p expression had tumorpromoting effects in colon cancer cells, which is in accordance with SIRT6 knockdown.

JAK2/STAT3 signaling pathway is activated in colon cancer cells by miRNA-34c-5p. As aforementioned, miRNA-34c-5p may promote proliferation and inhibit apoptosis by silencing SIRT6. However, whether miR-34c-5p exerts its functions via the JAK2/STAT3 signaling pathway remains to be elucidated. Therefore, the present study altered the 
A

p-JAK2

t-JAK2

p-STAT3

t-STAT3

Tubulin

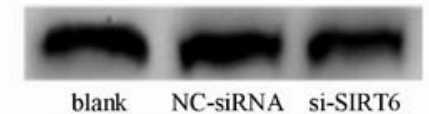

B

p-JAK2

t-JAK2

p-STAT3

t-STAT3

Tubulin
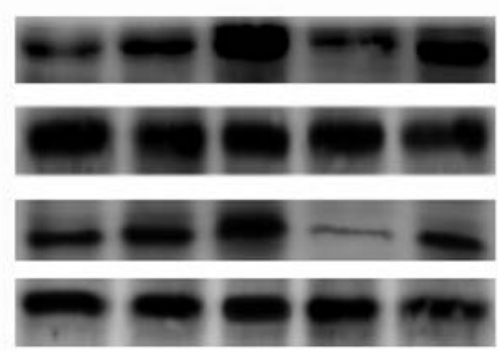

NC-siRNA DMSO si-SIRT6 AG490 si-SIRT6
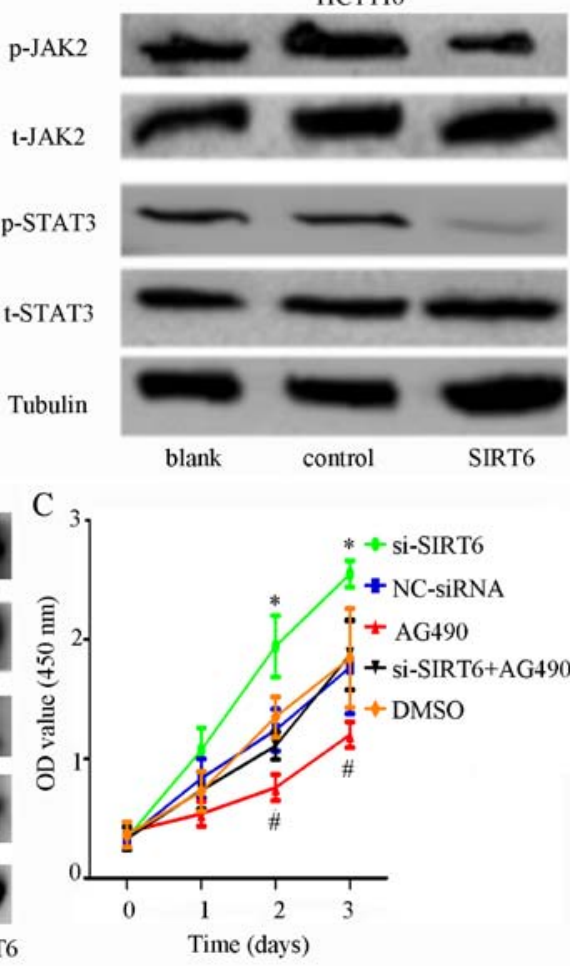

AG490

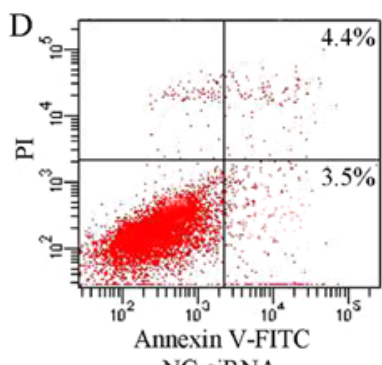

NC-siRNA

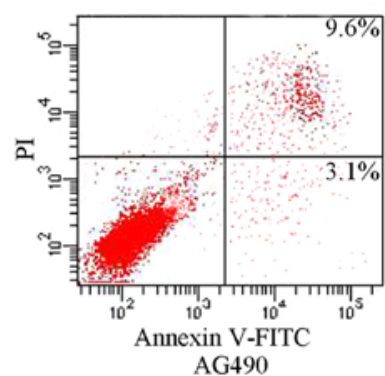

$\mathrm{E}$

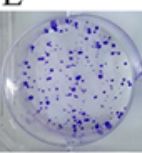

NC-siRNA

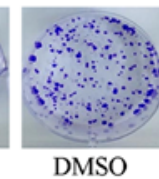

DMSO

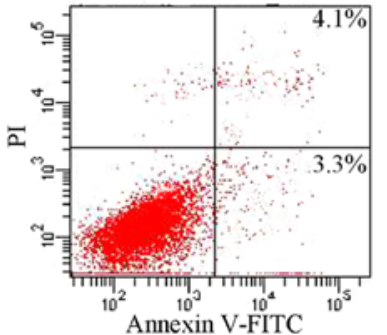

DMSO
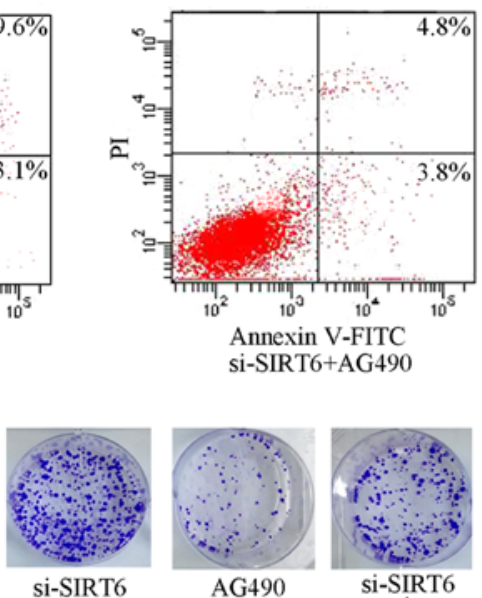

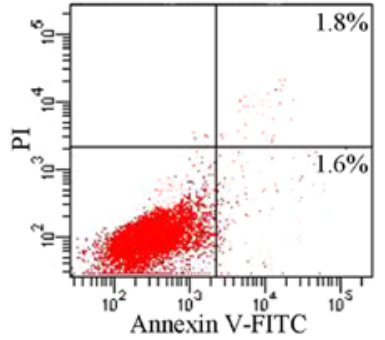

si-SIRT6
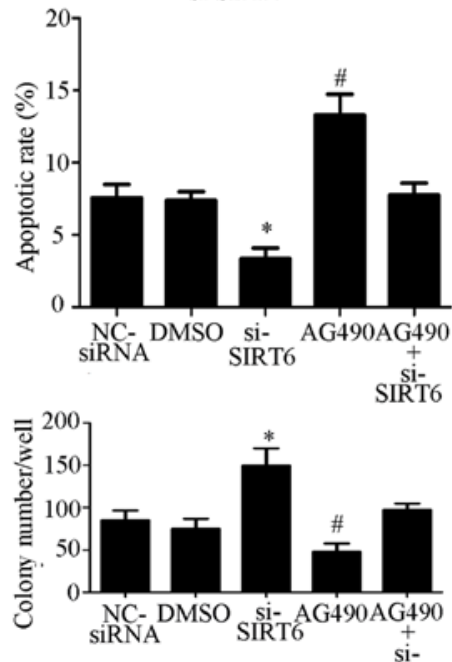

Si-
SIRT6

Figure 4. SIRT6 overexpression inhibits the JAK2/STAT3 signaling pathway in colon cancer cells. (A) Phosphorylation of JAK2 and STAT3 was increased in the si-SIRT6 group and inhibited in the SIRT6 group compared with the other groups. (B) Phosphorylation of JAK2 and STAT3 was activated by SIRT6 knockdown and inhibited by AG490 in RKO cell lines. However, transfection with si-SIRT6 abolished the effects of AG490, which further confirmed that SIRT6 may regulate the JAK2/STAT3 signaling pathways. (C) Proliferation rate was higher in the si-SIRT6 group and lower in the si-SIRT6 + AG490 group. The proliferation-inhibiting effects of AG490 were attenuated by si-SIRT6; "P $<0.05$, si-SIRT6 group vs. the other groups; "P $<0.05$, AG490 group vs. the other groups. (D) AG490 induced apoptosis of RKO cells, whereas si-SIRT6 exerted the opposite effect. However, the effects of AG490 were reversed by si-SIRT6; "P $<0.05$ vs. other groups; " $\mathrm{P}<0.05$ vs other groups. (E) Colony-forming ability was increased by SIRT6 knockdown and decreased by AG490. The effects of AG490 could be eliminated by SIRT6 knockdown; ${ }^{\text {P }}<0.05$ vs. the other groups; ${ }^{\prime} \mathrm{P}<0.05$ vs. the other groups. DMSO, dimethyl sulfoxide; FITC, fluorescein isothiocyanate; JAK2, Janus kinase 2; NC, negative control; OD, optical density; p-, phosphorylated; PI, propidium iodide; si/siRNA, small interfering RNA; SIRT6, sirtuin 6; STAT3, signal transducer and activator of transcription 3; t, total. 

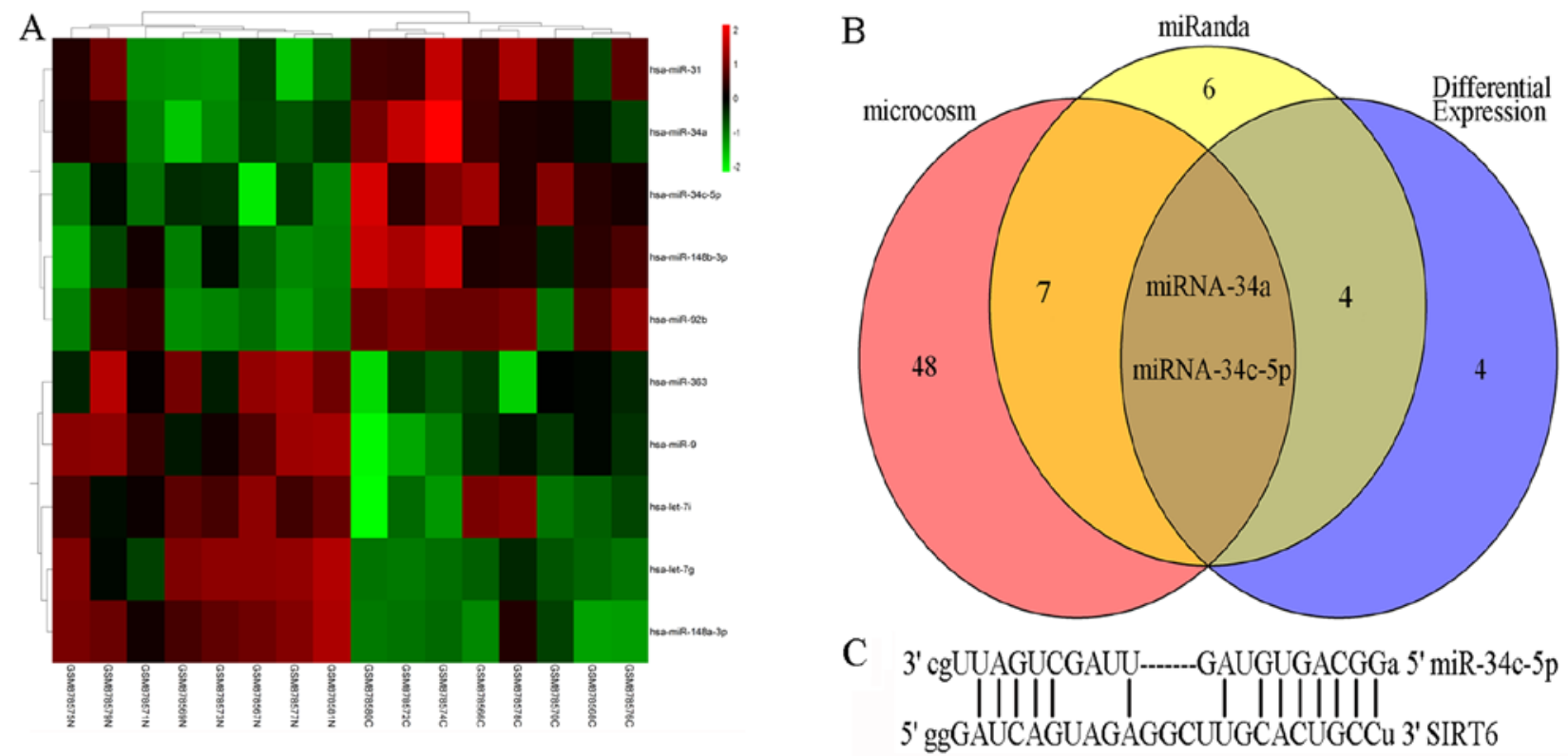

Figure 5. Bioinformatics analysis. (A) Cluster analysis of the differentially expressed miRNAs between colon cancer tissues (' $\mathrm{C}$ ') and adjacent tissues ('N') A total of 10 significant differentially expressed miRNAs (llog fold changel $>1.5$ and $\mathrm{P}<0.05$ ) are highlighted in green (downregulated) and red (upregulated). (B) Overlap analysis of miRanda, MicroCosm and differentially expressed miRNAs. miR-34c-5p and miR-34a are most likely to interact with the 3'-untranslated region of SIRT6 mRNA. (C) Potential binding sites of miR-34c-5p and SIRT6 mRNA. miR, microRNA; SIRT6, sirtuin 6.

A
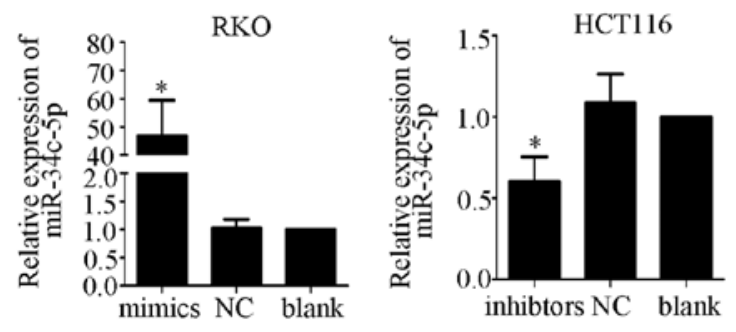

$\mathrm{B}$

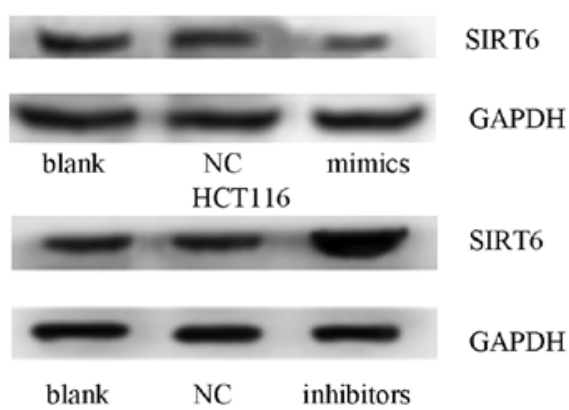

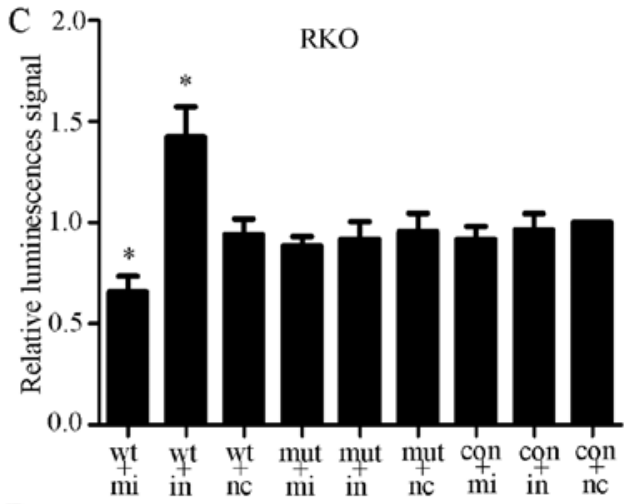

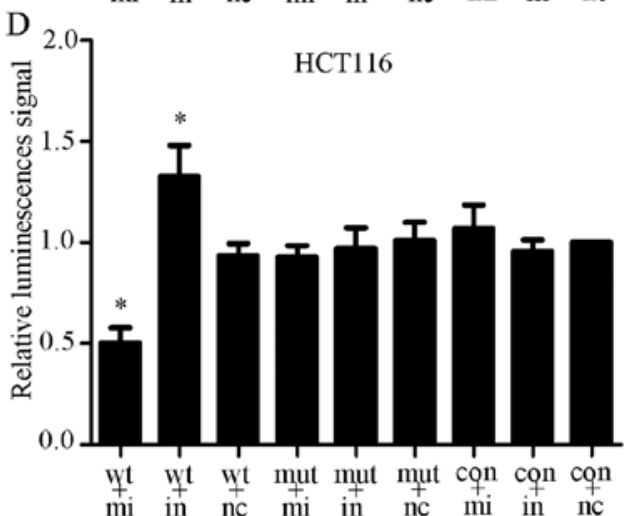

Figure 6. (A) Transfection efficiency was confirmed by quantitative polymerase chain reaction. miR-34c-5p mimics upregulated the expression of miR-34c-5p in RKO cells and miR-34c-5p inhibitors downregulated the expression of miR-34c-5p in HCT116 cells. (B) Effects of miRNA mimics and inhibitors on SIRT6 expression in colon cancer cell lines, as determined by western blot analysis. SIRT6 expression was suppressed by miR-34c-5p mimics and increased by inhibitors. (C and D) Dual-luciferase reporter assays used vectors encoding wt or mut putative miR-34c-5p target sites in the SIRT6 3'-UTR. Data were normalized by Renilla/Firefly luciferase activity. The relative luciferase activity of the mimics + wt group was clearly lower, and that of the inhibitors + wt group was significantly higher compared with the other groups; ${ }^{*} \mathrm{P}<0.05$ vs. other groups. con, control vector; in, inhibitors; mi, mimics; miR, microRNA; mut, mutant; NC, negative control; SIRT6, sirtuin 6.

expression of miR-34c-5p, in order to observe its effects on the JAK2/STAT3 signaling pathway. The results demonstrated that the JAK2/STAT3 signaling pathway was activated in the mimic group compared with in the NC and blank groups. 

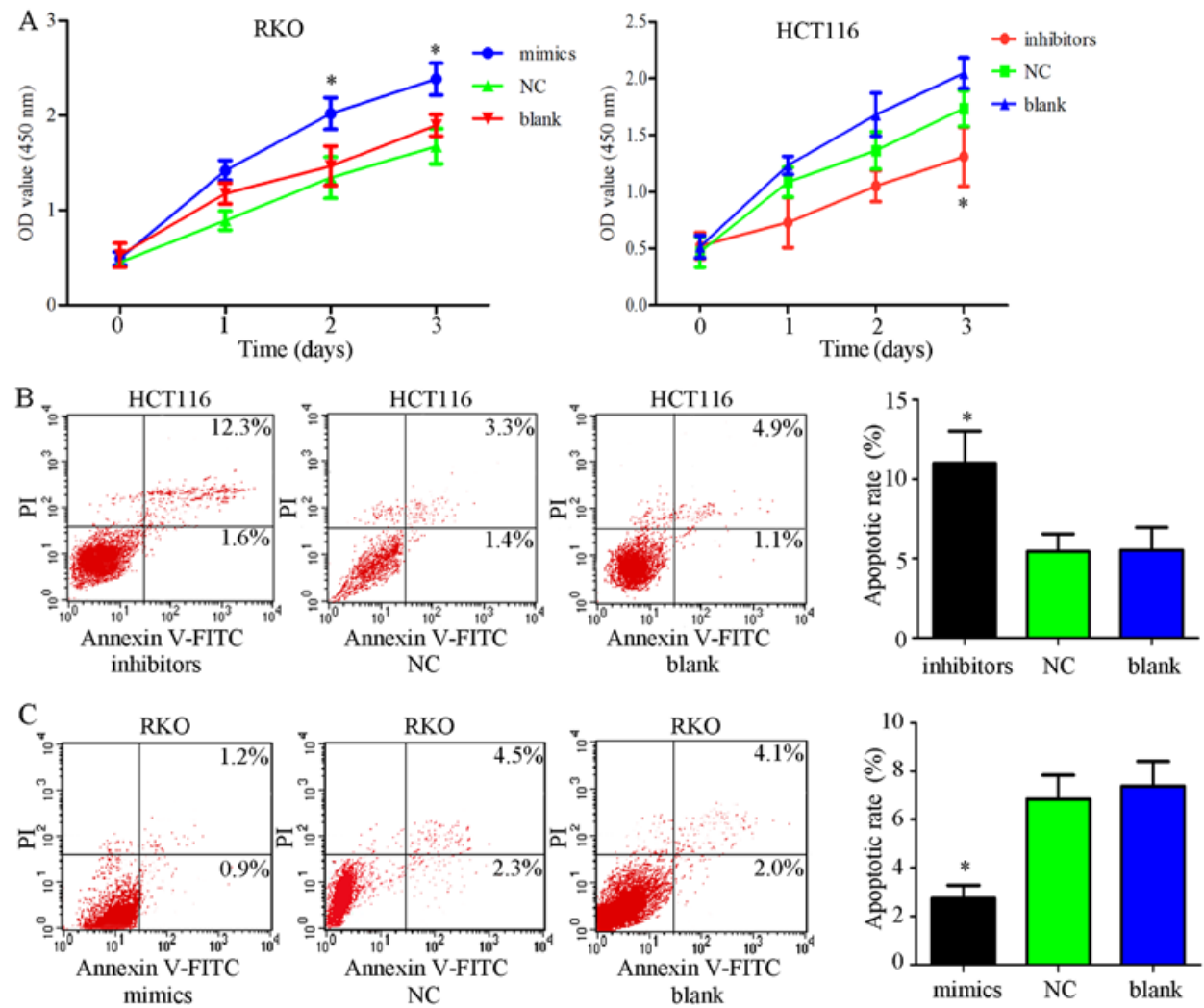

D

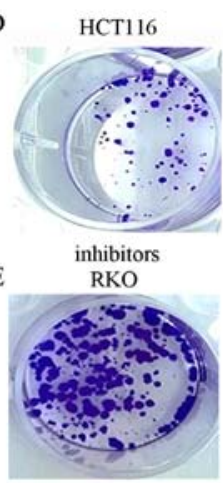

mimics
HCT116
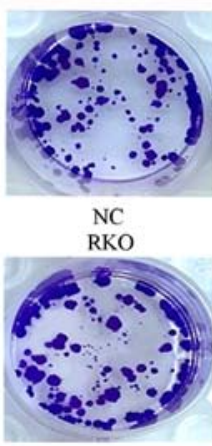

$\mathrm{NC}$
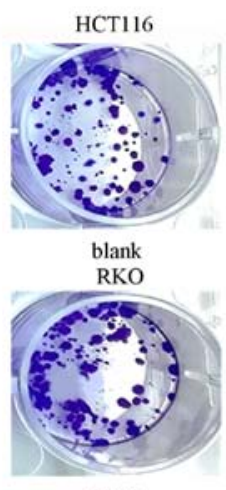

blank
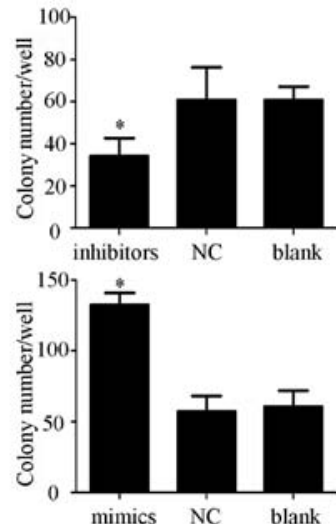

F

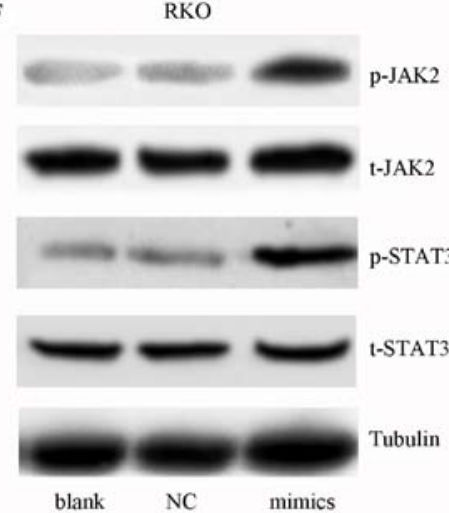

HCT116

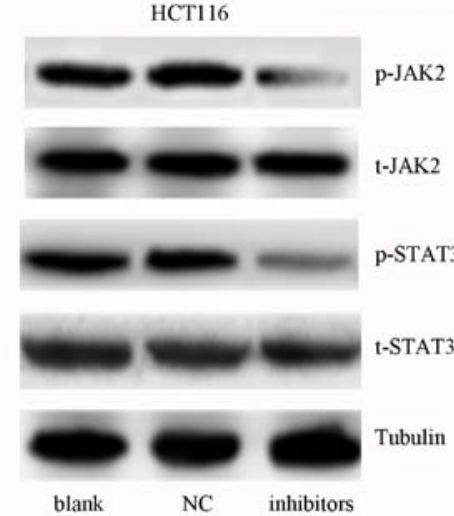

Figure 7. Effects of miR-34c-5p on colon cancer cells. (A) Cell viability was determined using Cell Counting kit-8 assays post-transfection with mimics or inhibitors in RKO or HCT116 cell lines. miR-34c-5p mimics facilitated cell growth compared with in the control groups, whereas miR-34c-5p inhibitors suppressed cell viability; ${ }^{*} \mathrm{P}<0.05$ vs. other groups. (B and C) Annexin V-FITC/PI was employed to estimate apoptosis post-transfection with miR-34c-5p mimics in RKO cells or miR-34c-5p inhibitors in HCT116 cells. The results indicated that cell apoptotic rate was decreased in the mimic group and increased in the inhibitor group compared with in the control groups; ${ }^{*} \mathrm{P}<0.05$ vs. other groups. (D and E) Compared with in the other groups, transfection with miR-34c-5p inhibitors inhibited colony formation, whereas miR-34c-5p mimics enhanced it; ${ }^{*} \mathrm{P}<0.05$ vs. other groups. (F) JAK2 and STAT3 phosphorylation was promoted by mimics and decreased by inhibitors compared with in the other groups. miR-34c-5p may promote cell growth and inhibit apoptosis via the JAK2/STAT3 pathways. FITC, fluorescein isothiocyanate; JAK2, Janus kinase 2; miR, microRNA; NC, negative control; OD, optical density; p-, phosphorylated; PI, propidium iodide; SIRT6, sirtuin 6; STAT3, signal transducer and activator of transcription 3; t total. 
Conversely, the phosphorylation of JAK2 and STAT3 was decreased in the inhibitor group compared with in the NC and blank groups (Fig. 7F). These data indicated that miRNA-34c-5p may exert tumor-promoting effects via activation of the JAK2/STAT3 signaling pathway.

\section{Discussion}

The SIRT family is involved in numerous biological processes, including apoptosis and aging (27-29). As a member of the SIRT family, SIRT6 serves versatile roles in human cancer. SIRT6 acts as a cancer suppressor gene in pancreatic cancer by controlling Lin-28 homolog B (30), and promotes cytokine production and migration in pancreatic cancer cells by regulating $\mathrm{Ca}^{2+}$ responses (31). Decreased expression of SIRT6 promotes tumor cell growth and is closely correlated with the poor prognosis of ovarian cancer, gastric cancer and glioma $(20,25,32)$. In nonsmall cell lung cancer, SIRT6 can suppress cell proliferation via the inhibition of Twist1, and astragaloside IV can sensitize non-small cell lung cancer cells to gefitinib by upregulating SIRT6 $(33,34)$. However, some studies have reported opposite findings. Azuma et al and Bai et al demonstrated that high SIRT6 expression is associated with poor prognosis and reduced chemosensitivity, and may promote cancer cell metastasis and invasion via the extracellular signal-regulated kinase (ERK)1/2/matrix metalloproteinase 9 pathway $(35,36)$. Notably, SIRT6 is upregulated and contributes to the progression of papillary thyroid cancer and hepatocellular carcinoma via numerous mechanisms (37-39). Similar to non-small cell lung cancer, the role of SIRT6 in hepatocellular carcinoma is controversial. It has previously been reported that SIRT6 suppresses hepatocellular carcinoma cell growth by inhibiting the ERK signaling pathway (40). However, studies focusing on the role of SIRT6 in the pathogenesis and prognosis of colon cancer are very limited. The majority of studies regarding SIRT6 and colon cancer have focused on the role of SIRT6 as a mediator at the cellular level, suggesting that SIRT6 may have an inhibitory effect on colon cancer (41-43).

In the present study, the correlation between SIRT6 and the clinical features of colon cancer were explored by tissue chip and IHC. The results demonstrated that SIRT6 was predominantly expressed in the nucleus, and its expression in colon cancer was significantly lower than in adjacent tissues. The correlation suggested that SIRT6 was negatively associated with $\mathrm{T}$ stage, and the prognosis of patients with colon cancer was significantly increased in those with high SIRT6 expression. Furthermore, Cox multivariate regression analysis indicated that SIRT6 expression was a protective independent prognostic factor.

T stage is mainly affected by proliferation and apoptosis. Since a correlation was detected between T stage and SIRT6 expression, the present study aimed to determine whether SIRT6 affected proliferation and apoptosis of colon cancer cells. RKO cells were revealed to possess a high expression of SIRT6, whereas HCT116 cells possessed low SIRT6 expression; these cell lines were selected for subsequent analyses. Using HCT116 cells in which SIRT6 overexpression was induced and RKO cells in which SIRT6 expression was knocked down, it was demonstrated that SIRT6 significantly attenuated proliferation and increased the levels of cell apoptosis. Furthermore, the results demonstrated that SIRT6 may inactivate the JAK2/STAT3 signaling pathway, which has previously been reported to induce the expression of B-cell lymphoma 2 (Bcl-2) and Bcl-extra large, and inhibit apoptosis $(21,25,44)$. The present study indicated that SIRT6 may act as a tumor suppressor gene in colon cancer, which may affect tumor size by regulating proliferation and apoptosis via the JAK2/STAT3 signaling pathway.

The present study demonstrated that the expression levels of SIRT6 were markedly decreased in cancer tissues; therefore, the present study aimed to determine the possible mechanisms underlying its downregulation. miRNAs are a type of small, non-coding RNA that regulate the expression of genes. Therefore, the present study investigated whether miRNAs are responsible for the dysregulation of SIRT6 in colon cancer. miRanda, MicroCosm and GEO databases were used to predict the miRNAs that may participate in SIRT6 regulation. The results indicated that miR-34c-5p may interact with the mRNA of SIRT6.

miRNA-34c-5p serves various roles in numerous types of cancer; miRNA-34c-5p can affect the drug resistance of ovarian, gastric and lung cancers (45-47). In addition, miRNA-34c-5p has been reported to be associated with recurrence in laryngeal squamous cell carcinoma, and the development and radioresistance of nasopharyngeal carcinoma (48-50). Furthermore, miR-34c-5p is involved in the proliferation, apoptosis and invasion of endometrial carcinoma, glioma cells and cervical cancer (51-53). However, the biological function of miRNA-34c-5p and its target genes in colon cancer remains to be elucidated.

Using dual-luciferase reporter assays, the present study confirmed that SIRT6 is a target of miR-34c-5p, and increased expression of $\mathrm{miR}-34 \mathrm{c}-5 \mathrm{p}$ may be responsible for the downregulation of SIRT6 in colon cancer. Furthermore, the overexpression of miRNA-34c-5p resulted in a marked reduction in cell apoptosis and enhanced proliferation via activation of the JAK2/STAT3 pathway. Conversely, knockdown of miRNA-34c-5p exhibited the opposite effects, which is consistent with silencing SIRT6 or ectopic overexpression of SIRT6.

To the best of our knowledge, the present study is the first to report the relationship between SIRT6 and the clinical features of colon cancer, and to explain the effects of miRNA on SIRT6 dysregulation. The present study also explored the biological function of miRNA-34c-5p and its mechanism in colon cancer. However, the patients involved in the present study may not be enough to draw a definite conclusion that SIRT6 is associated with prognosis and T stage. More patients with different stages of cancer and their follow-up data should be included in future studies. In addition, the present study only demonstrated that miRNA-34c-5p may promote proliferation and inhibit cell apoptosis through silencing SIRT6 and activating the JAK2/STAT3 signaling pathway; however, the in-depth mechanisms underlying how SIRT6 affects the JAK2/STAT3 signaling pathway and biological functions should be further investigated in in vitro and in vivo experiments.

In conclusion, the present study demonstrated that SIRT6 downregulation, partly due to the upregulation of miR-34c-5p, may promote colon cancer growth via activation of the JAK2/STAT3 signaling pathway, and SIRT6 is likely 
a biomarker for predicting the prognosis of colon cancer. Therefore, focusing on the miR-34c-5p/SIRT6/JAK2/STAT3 regulatory axis may be considered a promising strategy for the treatment of colon cancer.

\section{Acknowledgements}

Not applicable.

\section{Funding}

The present study was supported by the Liaoning Province Natural Science Foundation (grant nos. 201602293 and 201705400360).

\section{Availability of data and materials}

All data generated or analyzed during this study are included in this published article.

\section{Authors' contributions}

NL, FR and KL designed the research, analyzed the data, and wrote and revised the manuscript. DM, YC and HL performed the research. All authors have read and approved the final version of this manuscript.

\section{Ethics approval and consent to participate}

The human samples in the tissue chip were obtained from the National Human Genetic Resources Sharing Service Platform (2005KDA21300). All clinical samples described in the present study were obtained from patients who had provided written informed consent.

\section{Consent for publication}

Not applicable.

\section{Competing interests}

The authors declare that they have no competing interests.

\section{References}

1. Siegel RL, Miller KD and Jemal A: Cancer Statistics, 2017. CA Cancer J Clin 67: 7-30, 2017.

2. Lombard DB, Schwer B, Alt FW and Mostoslavsky R: SIRT6 in DNA repair, metabolism and ageing. J Intern Med 263: 128-141, 2008

3. Sebastián C, Satterstrom FK, Haigis MC and Mostoslavsky R: From sirtuin biology to human diseases: An update. J Biol Chem 287: 42444-42452, 2012.

4. Tennen RI and Chua KF: Chromatin regulation and genome maintenance by mammalian SIRT6. Trends Biochem Sci 36 39-46, 2011.

5. Michishita E, McCord RA, Berber E, Kioi M, Padilla-Nash H, Damian M, Cheung P, Kusumoto R, Kawahara TL, Barrett JC, et al: SIRT6 is a histone H3 lysine 9 deacetylase that modulates telomeric chromatin. Nature 452: 492-496, 2008.

6. Ran LK, Chen Y, Zhang ZZ, Tao NN, Ren JH, Zhou L, Tang H, Chen X, Chen K, Li WY, et al: SIRT6 overexpression potentiates apoptosis evasion in hepatocellular carcinoma via BCL2-associated X protein-dependent apoptotic pathway. Clin Cancer Res 22: 3372-3382, 2016.
7. Sebastián C, Zwaans BM, Silberman DM, Gymrek M, Goren A, Zhong L, Ram O, Truelove J, Guimaraes AR, Toiber D, et al: The histone deacetylase SIRT6 is a tumor suppressor that controls cancer metabolism. Cell 151: 1185-1199, 2012.

8. Min L, Ji Y, Bakiri L, Qiu Z, Cen J, Chen X, Chen L, Scheuch H, Zheng H, Qin L, et al: Liver cancer initiation is controlled by AP-1 through SIRT6-dependent inhibition of survivin. Nat Cell Biol 14: 1203-1211, 2012.

9. Marquardt JU, Fischer K, Baus K, Kashyap A, Ma S, Krupp M, Linke M, Teufel A, Zechner U, Strand D, et al: Sirtuin-6dependent genetic and epigenetic alterations are associated with poor clinical outcome in hepatocellular carcinoma patients. Hepatology 58: 1054-1064, 2013.

10. Lefort K, Brooks Y, Ostano P, Cario-André M, Calpini V, GuineaViniegra J, Albinger-Hegyi A, Hoetzenecker W, Kolfschoten I, Wagner EF, et al: A miR-34a-SIRT6 axis in the squamous cell differentiation network. EMBO J 32: 2248-2263, 2013.

11. Liu Y, Xie QR, Wang B, Shao J, Zhang T, Liu T, Huang G and Xia W: Inhibition of SIRT6 in prostate cancer reduces cell viability and increases sensitivity to chemotherapeutics. Protein Cell 4: 702-710, 2013.

12. Lau NC, Lim LP, Weinstein EG and Bartel DP: An abundant class of tiny RNAs with probable regulatory roles in Caenorhabditis elegans. Science 294: 858-862, 2001.

13. Lee RC and Ambros V: An extensive class of small RNAs in Caenorhabditis elegans. Science 294: 862-864, 2001.

14. Farazi TA, Hoell JI, Morozov P and Tuschl T: MicroRNAs in human cancer. Adv Exp Med Biol 774: 1-20, 2013.

15. Fu J, Tang W, Du P, Wang G, Chen W, Li J, Zhu Y, Gao J and Cui L: Identifying microRNA-mRNA regulatory network in colorectal cancer by a combination of expression profile and bioinformatics analysis. BMC Syst Biol 6: 68, 2012.

16. Dotto GP and Karine L: miR-34a/SIRT6 in squamous differentiation and cancer. Cell Cycle 13: 1055-1056, 2014.

17. Ding W, Hu W, Yang H, Ying T and Tian Y: Prognostic correlation between MTA2 expression level and colorectal cancer. Int J Clin Exp Pathol 8: 7173-7180, 2015.

18. Ritchie ME, Phipson B, Wu D, Hu Y, Law CW, Shi W and Smyth GK: limma powers differential expression analyses for RNA-sequencing and microarray studies. Nucleic Acids Res 43: e47, 2015.

19. Livak KJ and Schmittgen TD: Analysis of relative gene expression data using real-time quantitative PCR and the 2(-Delta Delta C(T)) Method. Methods 25: 402-408, 2001.

20. Feng J, Yan PF, Zhao HY, Zhang FC, Zhao WH and Feng M: SIRT6 suppresses glioma cell growth via induction of apoptosis, inhibition of oxidative stress and suppression of JAK2/STAT3 signaling pathway activation. Oncol Rep 35: 1395-1402, 2016.

21. Xu JH, Zhang C, Tang B, Hao YX, Chen J, Liu T and Cui H: Effect of JAK2/STAT3/vimentin signaling pathway on proliferation and migration of human colon cancer cells. Zhonghua Wei Chang Wai Ke Za Zhi 13: 282-285, 2010 (In Chinese).

22. Lu YM, Chen W, Zhu JS, Chen WX and Chen NW: Eriocalyxin B blocks human SW1116 colon cancer cell proliferation, migration, invasion, cell cycle progression and angiogenesis via the JAK2/ STAT3 signaling pathway. Mol Med Rep 13: 2235-2240, 2016.

23. Liu X, Ji Q, Ye N, Sui H, Zhou L, Zhu H, Fan Z, Cai J and Li Q: Berberine inhibits invasion and metastasis of colorectal cancer cells via COX-2/PGE2 mediated JAK2/STAT3 signaling pathway. PLoS One 10: e0123478, 2015.

24. Chae IG, Kim DH, Kundu J, Jeong CH, Kundu JK and Chun KS: Generation of ROS by CAY10598 leads to inactivation of STAT3 signaling and induction of apoptosis in human colon cancer HCT116 cells. Free Radic Res 48: 1311-1321, 2014.

25. Zhou J, Wu A, Yu X, Zhu J and Dai H: SIRT6 inhibits growth of gastric cancer by inhibiting JAK2/STAT3 pathway. Oncol Rep 38: 1059-1066, 2017.

26. Kara M, Yumrutas O, Ozcan O, Celik OI, Bozgeyik E, Bozgeyik I and Tasdemir S: Differential expressions of cancer-associated genes and their regulatory miRNAs in colorectal carcinoma. Gene 567: 81-86, 2015.

27. Kawahara TL, Michishita E, Adler AS, Damian M, Berber E, Lin M, McCord RA, Ongaigui KC, Boxer LD, Chang HY, et al: SIRT6 links histone H3 lysine 9 deacetylation to NF-kappaB-dependent gene expression and organismal life span. Cell 136: 62-74, 2009.

28. Xiao C, Kim HS, Lahusen T, Wang RH, Xu X, Gavrilova O, Jou W, Gius D and Deng CX: SIRT6 deficiency results in severe hypoglycemia by enhancing both basal and insulin-stimulated glucose uptake in mice. J Biol Chem 285: 36776-36784, 2010. 
29. Kim HS, Xiao C, Wang RH, Lahusen T, Xu X, Vassilopoulos A, Vazquez-Ortiz G, Jeong WI,Park O, Ki SH, et al: Hepatic-specific disruption of SIRT6 in mice results in fatty liver formation due to enhanced glycolysis and triglyceride synthesis. Cell Metab 12: 224-236, 2010.

30. Kugel S, Sebastián C, Fitamant J, Ross KN, Saha SK, Jain E, Gladden A, Arora KS, Kato Y, Rivera MN, et al: SIRT6 Suppresses Pancreatic Cancer through Control of Lin $28 \mathrm{~b}$. Cell 165: 1401-1415, 2016.

31. Bauer I, Grozio A, Lasigliè D, Basile G, Sturla L, Magnone M, Sociali G, Soncini D, Caffa I, Poggi A, et al: The NAD ${ }^{+}$ dependent histone deacetylase SIRT6 promotes cytokine production and migration in pancreatic cancer cells by regulating $\mathrm{Ca}^{2+}$ responses. J Biol Chem 287: 40924-40937, 2012.

32. Zhang G, Liu Z, Qin S and Li K: Decreased expression of SIRT6 promotes tumor cell growth correlates closely with poor prognosis of ovarian cancer. Eur J Gynaecol Oncol 36: 629-632, 2015.

33. Han Z, Liu L, Liu Y and Li S: Sirtuin SIRT6 suppresses cell proliferation through inhibition of Twist 1 expression in non-small cell lung cancer. Int J Clin Exp Pathol 7: 4774-4781, 2014.

34. Dai PC, Liu DL, Zhang L, Ye J, Wang Q, Zhang HW, Lin XH and Lai GX: Astragaloside IV sensitizes non-small cell lung cancer cells to gefitinib potentially via regulation of SIRT6. Tumour Biol 39: 1010428317697555, 2017.

35. Azuma Y, Yokobori T, Mogi A, Altan B, Yajima T, Kosaka T, Onozato R, Yamaki E, Asao T, Nishiyama M, et al: SIRT6 expression is associated with poor prognosis and chemosensitivity in patients with non-small cell lung cancer. J Surg Oncol 112: 231-237, 2015

36. Bai L, Lin G, Sun L, Liu Y, Huang X, Cao C, Guo Y and Xie C: Upregulation of SIRT6 predicts poor prognosis and promotes metastasis of non-small cell lung cancer via the ERK1/2/MMP9 pathway. Oncotarget 7: 40377-40386, 2016.

37. Qu N, Hu JQ, Liu L, Zhang TT, Sun GH, Shi RL and Ji QH: SIRT6 is upregulated and associated with cancer aggressiveness in papillary thyroid cancer via BRAF/ERK/Mcl 1 pathway. Int J Oncol 50: 1683-1692, 2017.

38. Tao NN, Ren JH, Tang H, Ran LK, Zhou HZ, Liu B, Huang AL and Chen J: Deacetylation of Ku70 by SIRT6 attenuates Bax-mediated apoptosis in hepatocellular carcinoma. Biochem Biophys Res Commun 485: 713-719, 2017.

39. Lee N, Ryu HG, Kwon JH, Kim DK, Kim SR, Wang HJ, Kim KT and Choi KY: SIRT6 Depletion Suppresses Tumor Growth by Promoting Cellular Senescence Induced by DNA Damage in HCC. PLoS One 11: e0165835, 2016.

40. Zhang ZG and Qin CY: Sirt6 suppresses hepatocellular carcinoma cell growth via inhibiting the extracellular signal regulated kinase signaling pathway. Mol Med Rep 9: 882-888, 2014.

41. Rizzo A, Iachettini S, Salvati E, Zizza P, Maresca C, D'Angelo C, Benarroch-Popivker D, Capolupo A, Del Gaudio F, Cosconati S et al: SIRT6 interacts with TRF2 and promotes its degradation in response to DNA damage. Nucleic Acids Res 45: 1820-1834, 2017.

42. Penrose H, Heller S, Cable C, Makboul R, Chadalawada G, Chen Y, Crawford SE and Savkovic SD: Epidermal growth factor receptor mediated proliferation depends on increased lipid droplet density regulated via a negative regulatory loop with FOXO3/ Sirtuin6. Biochem Biophys Res Commun 469: 370-376, 2016.
43. Lin Z, Yang H, Tan C, Li J, Liu Z, Quan Q, Kong S, Ye J, Gao B and Fang D: USP10 antagonizes c-Myc transcriptional activation through SIRT6 stabilization to suppress tumor formation. Cell Reports 5: 1639-1649, 2013.

44. Wang X, Qiu W, Zhang G, Xu S, Gao Q and Yang Z MicroRNA-204 targets JAK2 in breast cancer and induces cell apoptosis through the STAT3/BCl-2/survivin pathway. Int J Clin Exp Pathol 8: 5017-5025, 2015.

45. Tung SL, Huang WC, Hsu FC, Yang ZP, Jang TH, Chang JW, Chuang CM, Lai CR and Wang LH: miRNA-34c-5p inhibits amphiregulin-induced ovarian cancer stemness and drug resistance via downregulation of the AREG-EGFR-ERK pathway. Oncogenesis 6: e326, 2017.

46. Catuogno S, Cerchia L, Romano G, Pognonec P, Condorelli G and de Franciscis V: miR-34c may protect lung cancer cells from paclitaxel-induced apoptosis. Oncogene 32: 341-351, 2013.

47. Wu H, Huang M, Lu M, Zhu W, Shu Y, Cao P and Liu P: Regulation of microtubule-associated protein tau (MAPT) by miR-34c-5p determines the chemosensitivity of gastric cancer to paclitaxel. Cancer Chemother Pharmacol 71: 1159-1171, 2013.

48. Li G, Qiu Y, Su Z, Ren S, Liu C, Tian Y and Liu Y: Genome-wide analyses of radioresistance-associated miRNA expression profile in nasopharyngeal carcinoma using next generation deep sequencing. PLoS One 8: e84486, 2013.

49. Luo Z, Zhang L, Li Z, Li X, Li G, Yu H, Jiang C, Dai Y, Guo X, Xiang $\mathrm{J}$, et al: An in silico analysis of dynamic changes in microRNA expression profiles in stepwise development of nasopharyngeal carcinoma. BMC Med Genomics 5: 3, 2012.

50. Re M, Çeka A, Rubini C, Ferrante L, Zizzi A, Gioacchini FM, Tulli M, Spazzafumo L, Sellari-Franceschini S, Procopio AD, et al: MicroRNA-34c-5p is related to recurrence in laryngeal squamous cell carcinoma. Laryngoscope 125: E306-E312, 2015.

51. Li F, Chen H, Huang Y, Zhang Q, Xue J, Liu Z and Zheng F: miR-34c plays a role of tumor suppressor in HEC 1-B cells by targeting E2F3 protein. Oncol Rep 33: 3069-3074, 2015.

52. Wu Z, Wu Y, Tian Y, Sun X, Liu J, Ren H, Liang C, Song L, Hu H, Wang L, et al: Differential effects of miR-34c-3p and miR-34c-5p on the proliferation, apoptosis and invasion of glioma cells. Oncol Lett 6: 1447-1452, 2013.

53. López JA and Alvarez-Salas LM: Differential effects of miR-34c-3p and miR-34c-5p on SiHa cells proliferation apoptosis, migration and invasion. Biochem Biophys Res Commun 409: 513-519, 2011.

This work is licensed under a Creative Commons Attribution-NonCommercial-NoDerivatives 4.0 International (CC BY-NC-ND 4.0) License. 